\title{
Representações Sociais de Trabalho Offshore para Trabalhadores Embarcados e Implicações na Vida Familiar e Social
}

Representaciones Sociales De Trabajo Offshore Para Trabajadores Embarcados Y Implicaciones En La Vida Familiar Y Social

Social Representations Of The Offshore Work For Embedded Workers And Its Implications On Family And Social Life

Sabrine Mantuan dos Santos Coutinho

ORCID: https://orcid.org/0000-0003-3939-6594

Universidade Federal do Espírito Santo, Espírito Santo/Brasil

Paulo Rogério Meira Menandro

ORCID: https://orcid.org/0000-0003-3095-4959

Universidade Federal do Espírito Santo, Espírito Santo/ Brasil

Ana Carolina Caetano Tavares Moreira

ORCID: https://orcid.org/0000-0003-1247-6615

Universidade Federal do Espírito Santo, Espírito Santo/ Brasil

\begin{abstract}
Declaração de Direito Autoral
A submissão de originais para este periódico implica na transferência, pelos autores, dos direitos de publicação impressa e digital. Os direitos autorais para os artigos publicados são do autor, com direitos do periódico sobre a primeira publicação. Os autores somente poderão utilizar os mesmos resultados em outras publicações indicando claramente este periódico como o meio da publicação original. Em virtude de sermos um periódico de acesso aberto, permite-se o uso gratuito dos artigos em aplicações educacionais e científicas desde que citada a fonte conforme a licença CC-BY da Creative Commons.
\end{abstract}

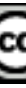

\section{Resumo}

O contexto de trabalho em plataformas de petróleo, em virtude do afastamento da costa por um período de tempo determinado, apresenta condições peculiares que, muitas vezes, exige arranjos por parte dos trabalhadores, sobretudo em relação à vida familiar e conjugal. Nesta perspectiva, a presente pesquisa dedicou-se a investigar como trabalhadores embarcados em plataformas de petróleo compreendem e vivenciam o trabalho offshore, bem como suas implicações para a vida familiar e social. Para tanto, adotou o referencial da Teoria das Representações Sociais (TRS). Foram entrevistados 25 pessoas que atuam ou já atuaram no ramo petrolífero embarcados em plataformas localizadas na Bacia de Campos dos Goytacazes/RJ. As entrevistas semiestruturadas abordaram dois blocos de questões: um relativo a dados pessoais e outro referente à relação entre o trabalho embarcado e aspectos da vida familiar e social. Os dados textuais das entrevistas foram submetidos ao software IRAMUTEQ. Os resultados apontam como principais dificuldades decorrentes do trabalho o afastamento da família e da vida social e a impossibilidade de participar de eventos cotidianos; como principais vantagens destacam-se a questão da folga e o retorno financeiro. Acredita-se que os resultados desta pesquisa podem contribuir para maior compreensão sobre a forma como o trabalho offshore é representado e vivenciado pelos trabalhadores.

Palavras-chaves: Trabalho offshore; Confinamento; Vida familiar e social; Representações sociais; Iramuteq 


\title{
Resumen
}

El contexto de trabajo en plataformas de petróleo, debido al alejamiento de la costa por un período de tiempo determinado, presenta condiciones peculiares que, muchas veces, exige arreglos por parte de los trabajadores, sobre todo en relación a la vida familiar y conyugal. En esta perspectiva, la presente investigación se dedicó a investigar cómo los trabajadores embarcados en plataformas de petróleo comprenden y experimentan el trabajo offshore, así como sus implicaciones para la vida familiar y social. Para ello, adoptó el referencial de la Teoría de las Representaciones Sociales (TRS). Se entrevistaron a 25 personas que actúan o ya actuaron en el ramo petrolífero embarcados en plataformas ubicadas en la Cuenca de Campos dos Goytacazes / RJ. Las entrevistas semiestructuradas abordaron dos bloques de preguntas: uno relativo a datos personales y otro referente a la relación entre el trabajo embarcado y aspectos de la vida familiar y social. Los datos textuales de las entrevistas fueron sometidos al software IRAMUTEQ. Los resultados apuntan como principales dificultades derivadas del trabajo el alejamiento de la familia y de la vida social y la imposibilidad de participar de eventos cotidianos; como principales ventajas se destacan la cuestión del juego y el retorno financiero. Se cree que los resultados de esta investigación pueden contribuir a una mayor comprensión sobre la forma en que el trabajo offshore es representado y vivido por los trabajadores.

Palabras claves: Trabajo offshore; Confinamento; Vida familiar y social; Representaciones sociales; Iramuteq.

\begin{abstract}
The context of work in oil platforms presents singular conditions that often require arrangements from workers, especially related to their families and married life, due to the distance between the platform and the coast for a certain period of time. From this point of view, this research was dedicated to investigate how these people who work on the board of oil platforms understand and experience the offshore work and its implications in their family and social life. For that purpose, it adopted the framework of the Social Representation Theory (SRT). Twenty-five workers from the oil industry that work or worked on the board of offshore oil platforms located at Campos dos Goytacazes/RJ Basin were interviewed. The semi-structured interviews have approached two blocks of questions: one concerning personal data and the other concerning the relationship between the work onboard and its consequences in the family and marriage. The textual data from the interviews were submitted to the software IRAMUTEQ. The results indicate that the main difficulty on this type of work is the gap that is created from the family and social life and the impossibility to participate on the everyday events; the main advantages include days off and the financial return. It is believed that the results from this research can contribute to a greater understanding of how the offshore work is represented and experienced by these workers.
\end{abstract}

Keywords: Offshore work; Confinement; Family and social life; Social representations; Iramuteq.

\section{Introdução}

A temática do trabalho offshore representa um campo fértil para estudos e investigações na área das ciências humanas e sociais. Por se tratar de um trabalho com características bastante peculiares, mostra-se relevante conhecer e compreender os significados atribuídos ao mesmo, bem como seus impactos na vida dos indivíduos.
Os trabalhadores de plataformas de petróleo, por realizarem suas atividades em alto mar, são denominados trabalhadores offshore (Pessanha, 1994; Pena, 2002). Offshore é um termo da língua inglesa que significa "no mar ou sobre o mar, distante da terra" (Webster Dictionary, 1978, p. 1243), indicando, portanto, atividade que se situa ou ocorre em alto mar. O fato de se dar longe da costa, em plataformas marítimas distantes do continente, confere uma 
particularidade a esse tipo de trabalho: o trabalhador, ao final do dia, precisa permanecer no mesmo espaço onde realizou suas atividades laborais, ou seja, há uma "fusão entre os espaços privados e públicos" (Pena, 2002). Além de estarem inseridos na indústria do petróleo, os trabalhadores offshore também se encontram na marinha mercante, na marinha de guerra e na pesca oceânica (Martins, 2007).

De acordo com Booth e Butler (1992, citados por Freitas, Souza, Machado, \& Porto (2001, p. 119), "plataformas de petróleo são instalações bastante complexas e algumas, principalmente as grandes plataformas, podem incluir a produção e armazenagem de óleo e gás à alta pressão, a perfuração de poços e obras de construção e manutenção". Freitas et al. (2001), destacando orientações da Organização Internacional do Trabalho (OIT), mencionam que as plataformas

Por operarem distantes da costa e de socorros imediatos, necessitam de certo grau de autonomia, exigindo-se um conjunto de serviços tais como alimentação e alojamento das tripulações (por vezes para mais de 200 pessoas embarcadas ao mesmo tempo), fornecimento de energia elétrica, compressores e bombas, água, transportes para a costa (barcos ou helicópteros), meios para cargas e descargas, telecomunicações, serviços médicos e botes salva-vidas, além de outros meios de salvamento, o que requer um elevado nível de coordenação (p. 119).

Sobre as principais instalações marítimas da indústria do petróleo, Martins (2007, p. 12) destaca:

as unidades de perfuração e produção marítima (balsas, navios, plataformas, sondas moduladas), as unidades de

\footnotetext{
1 Empresa criada em 1953, quando se instituiu o monopólio estatal do petróleo no Brasil (Souza, 1996). Inicialmente, a exploração era feita em terra (onshore), mas algumas décadas depois passou a se dar no fundo do mar, onde observou-se que está a parte mais significativa
}

produção de óleo e gás (plataformas fixas, plataformas flutuantes, navios de produção, armazenamento e descarga e navios cisternas), os navios petroleiros, os barcos de serviços especiais (sísmica, mergulho, robôs, lançamento de linhas, etc), além de variados barcos para fins diversos transporte de cargas, reboque de unidades, manuseio de âncoras, resgate, controle de poluição, combate a incêndio e transporte de passageiros.

No Brasil, o maior polo de plataformas marítimas e, consequentemente, maior polo produtor de petróleo e gás está localizado no litoral do Rio de Janeiro, na Bacia de Campos (Souza, 1996), com uma produção diária de aproximadamente "um milhão e quinhentos de barris de petróleo e de 23 milhões de metros cúbicos de gás" e com uma população offshore estimada em 40 mil trabalhadores, sendo 4 mil da operadora estatal Petrobras, com mais de 40 plataformas petrolíferas" (Martins, 2007, p. 11). A Petrobrás Petróleo Brasileiro $S / \mathrm{A}^{1}$ se instalou no litoral norte fluminense no final da década de 1970, época em que a região passava por grave crise na economia, que durante séculos se estruturou na produção de açúcar e álcool. Logo, a chegada da estatal foi vista como oportunidade para a retomada do crescimento regional. "Oferecendo inúmeras vantagens - dos salários vultosos ao prestígio alicerçado no seu status de empresa de alta tecnologia - a Petrobrás 'vira' a cabeça dos garotos da região, tornando-se o modelo de emprego a ser alcançado, mediante concurso e qualificação cada vez mais especializada" (Farias, 2008, p. 5).

Contudo, esse panorama sofreu alterações na década de 1990 quando vários serviços, antes executados por funcionários da estatal, passaram a ser terceirizados. Tanto é que, atualmente, menos de um terço dos

das reservas de petróleo brasileiras. A Petrobras é líder mundial em produção em águas profundas (Martins, 2007). 
trabalhadores que atuam na Bacia de Campos são funcionários da Petrobrás; a esmagadora maioria está vinculada a empresas prestadoras de serviços (chamadas terceirizadas ou empreiteiras) à estatal petrolífera (Farias, 2008).

Souza (1996) explica que a execução do trabalho em plataformas, no Brasil, se dá por meio de escala de revezamento em turnos de 12 horas (caso de funções técnicas desenvolvidas por trabalhadores de nível médio), ou de escala de sobreaviso (supervisores e profissionais de nível superior). Destaca também que o regime de dias embarcados por dias de descanso, atualmente, corresponde a um período de 14 dias ininterruptos de trabalho na plataforma por 14 ou 21 dias de folga. Essa variação decorre do fato de que para os funcionários da Petrobrás, a Constituição de 1988 estabeleceu o regime de 14 por 20 dias, ao passo que nas empresas privadas contratadas, permanece em vigor o antigo sistema de 14 dias de trabalho por 14 de descanso (Farias, 2008).

Conforme destacam Silva Junior e Ferreira (2007), os profissionais na área petrolífera são regidos pela lei 5.811/72, que instituiu maior remuneração devido ao trabalho noturno e ao perigo ao qual estão expostos, assim como maior tempo de repouso e descanso semanal, entre outros adicionais. Apesar de a referida lei garantir alguns direitos, Coelho e Paparelli (2010), referenciados em Castro e Nunes (2008), destacam que ainda há necessidade de outras conquistas no contexto do trabalho offshore na medida em que as dificuldades do trabalho nas plataformas marítimas vão além das condições ambientais, abarcando questões que incidem sobre a qualidade de vida e saúde mental dos sujeitos (a presença de transtornos mentais, como quadros de ansiedade, são ocorrências comuns). Carvalho (2010) destaca os impactos que o trabalho offshore pode causar na vida dos trabalhadores. A distância da costa e a impossibilidade de sair da embarcação a qualquer momento, a comunicação restrita, o afastamento do convívio social e familiar constituem fatores diferenciadores desse tipo de trabalho, que podem ser sintetizados na ideia de confinamento.

Segundo o Dicionário Houaiss da Língua Portuguesa (Houaiss \& Villar, 2001), confinar, entre outras acepções, significa "obrigar alguém (ou a si mesmo) a ficar num espaço delimitado, encerrar(-se)" (p. 796). Nesse mesmo sentido, confinamento está sendo utilizado no presente estudo como relacionado a um contexto específico de trabalho, como "toda essa conjuntura de trabalho, que afasta os trabalhadores do meio maior de convívio social e os limita em relação a uma movimentação maior por um período determinado de tempo" (Carvalho, 2010, pp. 39-40). Além de restringir as possibilidades de deslocamento do trabalhador dentro de um espaço físico delimitado, o confinamento deixa-o exposto durante todo o tempo (mesmo durante o repouso ou lazer) a vibrações, ruídos/barulhos e conversas constantes (Souza, 1996). Nas palavras de Salles e Costa (2012), "o trabalho confinado pode ser referido como uma vivência total no local de trabalho, que estabeleceria, para o trabalhador, uma rotina de vida profissional e pessoal diferenciada da maioria das pessoas" (p. 231).

Coelho e Paparelli (2010), em trabalho sobre gerenciamento de estresse em plataformas, definem confinamento - com base nas considerações de Rodrigues (2001), mencionadas por Castro e Nunes (2008) - como "limitação de espaço e impedimento do desejo de ir e vir, assim como isolamento social, distanciamento da família, principalmente em eventos com grande significado simbólico, ausência de privacidade enquanto embarcado e abstinência sexual forçada" ( $\mathrm{s} / \mathrm{p})$.

Outra questão apontada em relação a esse tipo de trabalho são os riscos. Freitas et al. (2001), ao estudarem os acidentes de trabalho em unidades de processo como as plataformas de petróleo, descrevem as características do trabalho nesses locais, destacando, com base em Ferreira e Igutti (1996), que devem ser 
considerados para sua compreensão quatro aspectos que se inter-relacionam e o caracterizam: trata-se de trabalho que é, simultaneamente, contínuo, complexo, coletivo e perigoso. Freitas et al. (2001, p. 119) detalham cada um desses aspectos. É trabalho contínuo uma vez que a produção flui durante as 24 horas do dia ao longo do ano, exigindo o revezamento de vários grupos de trabalhadores para acompanhamento da mesma. É complexo porque as diversas partes do sistema tecnológico se encontram interligadas em estrutura de rede que impede controle total do sistema, sempre sujeito a certo grau de imprevisibilidade e de desencadeamento de efeitos do tipo dominó em caso de incidentes e acidentes. É coletivo porque o funcionamento da unidade só é possível pelo trabalho de equipes cujas atividades são altamente interdependentes. E é perigoso porque envolve processamento de hidrocarbonetos que evaporam e que podem incendiar-se ou explodir, exige uso de compostos químicos tóxicos para os homens e para o ambiente e implica a operação de máquinas e equipamentos que podem desencadear acidentes poderosos, com o potencial de causar múltiplos óbitos e lesões.

Salles (2010, p. 38) destaca a "natureza estressante" desse tipo de trabalho, que abrange: "ambiente físico adverso; mares agitados; riscos nas viagens de helicóptero e de barco; exposição a barulho e acidentes; atividades físicas árduas; vida monótona dentro de um espaço limitado; isolamento social".

Pena (2002), em estudo que investigou as consequências do confinamento no trabalho e suas relações com o stress, com as emoções e com os distúrbios do sono nos trabalhadores, enfatiza que "a saudade e a solidão foram os principais sentimentos vivenciados pelos trabalhadores, apesar de as pessoas reprimirem essas emoções por temerem a reprovação alheia" (s/p). O autor também identificou aumento da ansiedade em função das condições de isolamento e confinamento, o que está diretamente relacionado com as principais dificuldades mencionadas pelos participantes: isolamento pessoal, distância da família e ausência de convívio social externo. Outra dificuldade mencionada diz respeito à questão das diferenças salariais entre contratados (trabalhadores terceirizados) e petroleiros (funcionários da Petrobras), e à relação hierarquizada entre eles, o que contribui para o distanciamento entre os dois grupos de trabalhadores (Pena, 2002).

Vale notar que, a maior parte dos estudos que abordam a questão do trabalho embarcado é desenvolvida na perspectiva da saúde do trabalhador ou com foco no ambiente e cultura organizacional. Mesmo em tais perspectivas, constata-se baixa produção de estudos (Coelho \& Paparelli, 2010), sendo a maior parte do início dos anos 2000. Por se tratar de atividade de expressiva relevância econômica para o país - a produção na Bacia de Campos "é responsável por $2,6 \%$ do PIB nacional, valor que praticamente equivale a toda a cadeia produtiva da indústria automobilística do país" (Martins, 2007, p. 11) - e que envolve, como mencionado anteriormente, grande contingente de trabalhadores que atuam sob condições peculiares, entende-se que são necessárias cada vez mais investigações com foco nas especificidades desse tipo de trabalho e em suas implicações na vida dos trabalhadores. Com isso, entende-se que o estudo desse fenômeno num enfoque psicossociológico pode trazer importantes contribuições, uma vez que possibilita “identificar a 'visão de mundo' que os indivíduos ou grupos têm e empregam na forma de agir e se posicionar" (Chaves \& Silva, 2011, p. 300) frente a esse tipo de trabalho.

Nesta perspectiva, a presente pesquisa pretendeu investigar como trabalhadores embarcados em plataformas de petróleo compreendem e vivenciam o trabalho offshore, bem como suas implicações para a vida familiar e social. Para tanto, adotou o referencial da Teoria das Representações Sociais (TRS) como aporte teórico na medida em que tal teoria se interessa pelo conhecimento produzido pelo senso comum no dia a dia, numa tentativa constante de compreender e lidar com realidade. 
Moscovici (2003) propõe que essas teorias de senso comum, por ele denominadas de representações sociais (RS), têm a finalidade primeira de tornar familiar algo não familiar, de modo que "em seu todo, a dinâmica das relações é uma dinâmica de familiarização, onde os objetos, pessoas e acontecimentos são percebidos e compreendidos em relação a prévios encontros e paradigmas" (p. 55). Ou seja, é uma dinâmica em que padrões de referência pré-estabelecidos possibilitam a inclusão do que é estranho, incomum, num sistema conhecido/familiar, tornando-o inteligível.

Nas palavras esclarecedoras de Moscovici (1976, citado por Duveen, 2003, p. 21), as RS constituem

um sistema de valores, ideias e práticas, com uma dupla função: primeiro, estabelecer uma ordem que possibilitará às pessoas orientar-se em seu mundo material e social e controlá-lo; e, em segundo lugar, possibilitar que a comunicação seja possível entre os membros de uma comunidade, fornecendo-lhes um código para nomear e classificar, sem ambiguidade, os vários aspectos de seu mundo e da sua história individual e social.

É importar compreender a amplitude do conceito moscoviciano de RS; estas não atuam apenas na interpretação da realidade, que orienta nossas ações, práticas e comunicações; na verdade, as RS, segundo Jodelet (2001), interferem em processos variados, que envolvem "difusão e assimilação de conhecimento, desenvolvimento individual e coletivo, definição das identidades pessoais e sociais, expressão dos grupos e das transformações sociais". (p. 22).

Além de sua função primordial de tornar familiar o não familiar (Moscovici, 1961/2012), as RS possuem importantes funções na dinâmica das relações sociais e nas práticas (Abric, 2000): de saber (compreensão e explicação da realidade), de orientação (guia de comportamentos e práticas), identitária (definição da identidade e proteção da especificidade grupal) e justificadora (justificação das tomadas de posição e comportamentos)

Considerando as mencionadas especificidades/ particularidades do trabalho offshore, bem como as diferentes funções de uma RS, compreende-se que tal modalidade de trabalho pode se constituir objeto de RS uma vez que, além de ter relevância na vida dos indivíduos, está inserido em suas trocas comunicacionais cotidianas (gera polêmica e discussão), e contribui para a constituição identitária dos sujeitos e para diferentes tomadas de posição. Em outras palavras, o trabalho offshore suscita visões de mundo que auxiliam os sujeitos e grupos no modo como o compreendem, o explicam e agem frente ao mesmo e frente a outros objetos relacionados, o que favorece a comunicação, a interação e as práticas cotidianas.

Sendo assim, a presente investigação dedicou-se a conhecer as RS de trabalho offshore para trabalhadores que atuam em plataformas marítimas de petróleo, bem como suas experiências, partindo do pressuposto de que esse tipo de trabalho, por sua própria natureza, produz implicações diretas não apenas na vida profissional dos sujeitos que o exercem, mas também nas esferas familiar e social das quais são parte.

\section{Método}

Participaram da pesquisa 25 pessoas, de ambos os sexos, que atuam ou atuavam (aposentados) embarcados em plataformas localizadas na Bacia de Campos/RJ, que é responsável por $80 \%$ da produção nacional de Petróleo (Farias, 2008).

Os participantes, em sua maioria, foram indicados por pessoas próximas dos pesquisadores, constituindo uma amostra intencional e de conveniência. Como estratégia adicional de acesso a prováveis participantes, também foi solicitado e autorizado o acesso ao 
Sindipetro Norte Fluminense (Sindipetro-NF) ${ }^{2}$, onde as pessoas filiadas eram abordadas e orientadas quanto aos objetivos da pesquisa visando uma possível adesão.

Os contatos realizados para a obtenção de participantes revelaram grande dificuldade para conseguir participantes do sexo feminino, o que espelha a realidade de que em tal condição de trabalho o contingente de trabalhadores envolvidos é predominantemente masculino. É sabido, inclusive, que algumas empresas terceirizadas proíbem a contratação de mulheres, conforme observado por Farias (2008). Resultou, assim, que 21 dos 25 participantes são homens. Desses homens, nove são (ou foram) funcionários da empresa Petrobrás, e 12 atuam (ou atuaram) em empresas privadas prestadoras de serviços terceirizados (que serão referidas como empresas terceirizadas). Dos vinculados à Petrobrás, cinco estão na ativa e quatro estão aposentados. Dos vinculados às empresas privadas, dez estão ativos e dois aposentados. Assim, dos 25 participantes, 6 são aposentados.

Quanto à faixa etária, os homens assim se distribuíram: quatro entre 25 e 35 anos; cinco entre 36 e 45; doze com 46 anos ou mais, estando o mais velho com 59 anos. Em relação ao estado civil, três são solteiros, dezesseis casados e dois divorciados. Têm filhos dezesseis dos participantes: três têm um filho, seis têm dois filhos, três têm três filhos e quatro têm quatro ou mais filhos. Sobre escolaridade, apenas um concluiu o ensino superior, seis iniciaram e não concluíram tal nível de ensino, dez concluíram o ensino médio, dois concluíram o ensino fundamental, e dois não responderam.

As quatro mulheres que participaram do estudo estão na ativa, atuando em empresas terceirizadas. Quanto à idade, a mais nova tem 21 anos e a mais velha 42. Duas delas são solteiras, uma é casada e uma é divorciada. Apenas uma delas têm filhos (2). Uma tem

\footnotetext{
${ }^{2}$ Sindicato dos Petroleiros do Norte Fluminense - criado
} em 1995 para atender as demandas dos trabalhadores da ensino superior completo, uma iniciou e não concluiu ensino superior, e duas concluíram o nível de ensino médio.

Os dados foram obtidos a partir de entrevista semiestruturada apoiada em roteiro que incluía solicitação de dados sociodemográficos, além de questões diversas relativas ao trabalho: o que pensa sobre o trabalho embarcado; quais são as atividades desenvolvidas no trabalho; quais são as atividades de lazer realizadas no contexto da plataforma; o que considera como principais vantagens e desvantagens do trabalho offshore; se há e quais são as interferências na vida familiar, conjugal e social; quais são as percepções da família sobre esse trabalho; como é a relação com os colegas de trabalho; como caracteriza a relação entre os trabalhadores de diferentes empresas na plataforma; entre outras questões eventuais, suscitadas por informações proporcionadas pelos entrevistados.

Foi estabelecido contato com os indivíduos indicados/localizados para que pudessem ser explicados os objetivos e os procedimentos do estudo, e para agendamento das entrevistas nos casos de interesse e concordância em participar. As entrevistas foram agendadas conforme a disponibilidade dos participantes, e foram realizadas em locais de conveniência dos mesmos, tais como em sua própria residência, na universidade, no sindicato, entre outros, sempre no período de folga dos mesmos. Antes do início da entrevista era apresentado o TCLE para participação em pesquisa, e após leitura e concordância, era solicitada assinatura em duas vias, assim como a permissão para uso de gravador de áudio.

A pesquisa foi realizada considerando a Resolução n. 466/2012 (Conselho Nacional de Saúde - CNS, 2012), o código de ética profissional do psicólogo (Conselho Federal de Psicologia - CFP), e foi autorizada pelo Comitê de Ética em Pesquisa da Universidade Federal

Bacia de Campos de ter uma estrutura sindical mais eficaz de representação na região Recuperado de http://www.sindipetronf.org.br/o-sindicato/historico 
Fluminense (Parecer Consubstanciado n. 872.740).

O material textual resultante das transcrições das entrevistas foi agrupado em um corpus, que foi submetido às análises realizadas por meio do software IRAMUTEQ (Interface de $R$ pour les Analyses Multidimensionnelles de Textes et de Questionnaires) versão 0.6. Trata-se de um programa computacional que possibilita diferentes formas de processamento e organização de dados textuais que contribuem para a análise. Uma modalidade desses processamentos é a constituída por operações básicas como cálculos de frequência e percentuais de palavras ou radicais (o que só é possível pelo fato do software contar com um dicionário). Outra modalidade é a identificação de classes de palavras que agrupam segmentos de texto que co-ocorrem e que diferem em algum grau de outras classes (incluindo cálculo do grau de associação das palavras às classes). O procedimento possibilita o uso da técnica de classificação hierárquica descendente (CHD), cujo resultado é apresentado em forma de dendrograma (Reinert, 1990). Trata-se de técnica que, adicionalmente, calcula o percentual de palavras que duas ou mais classes específicas compartilham, e faculta a recuperação dos segmentos de texto associados com cada classe, o que contextualiza e torna mais segura a interpretação dos conteúdos de cada classe. Diferentes segmentos de texto podem ser associados às variáveis de interesse para a pesquisa que estiver sendo feita (por exemplo, sexo ou idade) de forma que tais variáveis são consideradas nas análises que o IRAMUTEQ efetua (Camargo \& Justo, 2013a). A CHD, portanto, além de possibilitar exame lexical do material textual, oferece contextos de sentido das palavras (classes lexicais), que são caracterizados por um vocabulário específico e por segmentos de texto a eles associados
(Camargo \& Justo, 2013a). Na pesquisa aqui relatada foram empregadas as análises lexical, de especificidade e a CHD.

$\mathrm{Na}$ preparação do banco de dados, composto pelas transcrições das 25 entrevistas, foram informadas como variáveis a serem consideradas pelo software o sexo do entrevistado, o tipo de empresa (Petrobrás ou terceirizada) em que atua/atuou, e sua condição de ativo ou aposentado.

Cabe destacar que o programa não realiza, por si só, a análise dos dados, cabendo ao próprio pesquisador fazer as inferências com base no conhecimento que tem do material como um todo (Camargo \& Justo, 2013a).

\section{Resultados}

O programa IRAMUTEQ fracionou $\mathrm{o}$ corpus em 1.108 segmentos de texto, dos quais 971 foram aproveitados no procedimento de CHD, o que representa $87,64 \%$ do corpus. O corpus, em uma primeira etapa do processamento $\left(1^{\mathrm{a}}\right.$ partição), foi separado em dois subcorpora com compartilhamento de itens inexpressivo. O menor deles não sofreu alteração com a continuidade do processamento e constituiu, ao final, a classe 5. O subcorpus maior, deu origem, em nova etapa de processamento ( $2^{\mathrm{a}}$ partição) a classe 4 , e num processamento seguinte ( $3^{a}$ partição), originouse o subgrupamento constituído pela classe $1 \mathrm{e}$ pelas classes 3 e 2, que formaram um outro subgrupamento (4 $4^{\mathrm{a}}$ partição). Segundo Camargo e Justo (2013b), a CHD é finalizada quando as classes se mostram estáveis, isto é, compostas de segmentos de texto com vocabulário semelhante. A Figura 1 explicita essas etapas dos processamentos descritos e a Figura 2 as palavras que caracterizam cada classe. 


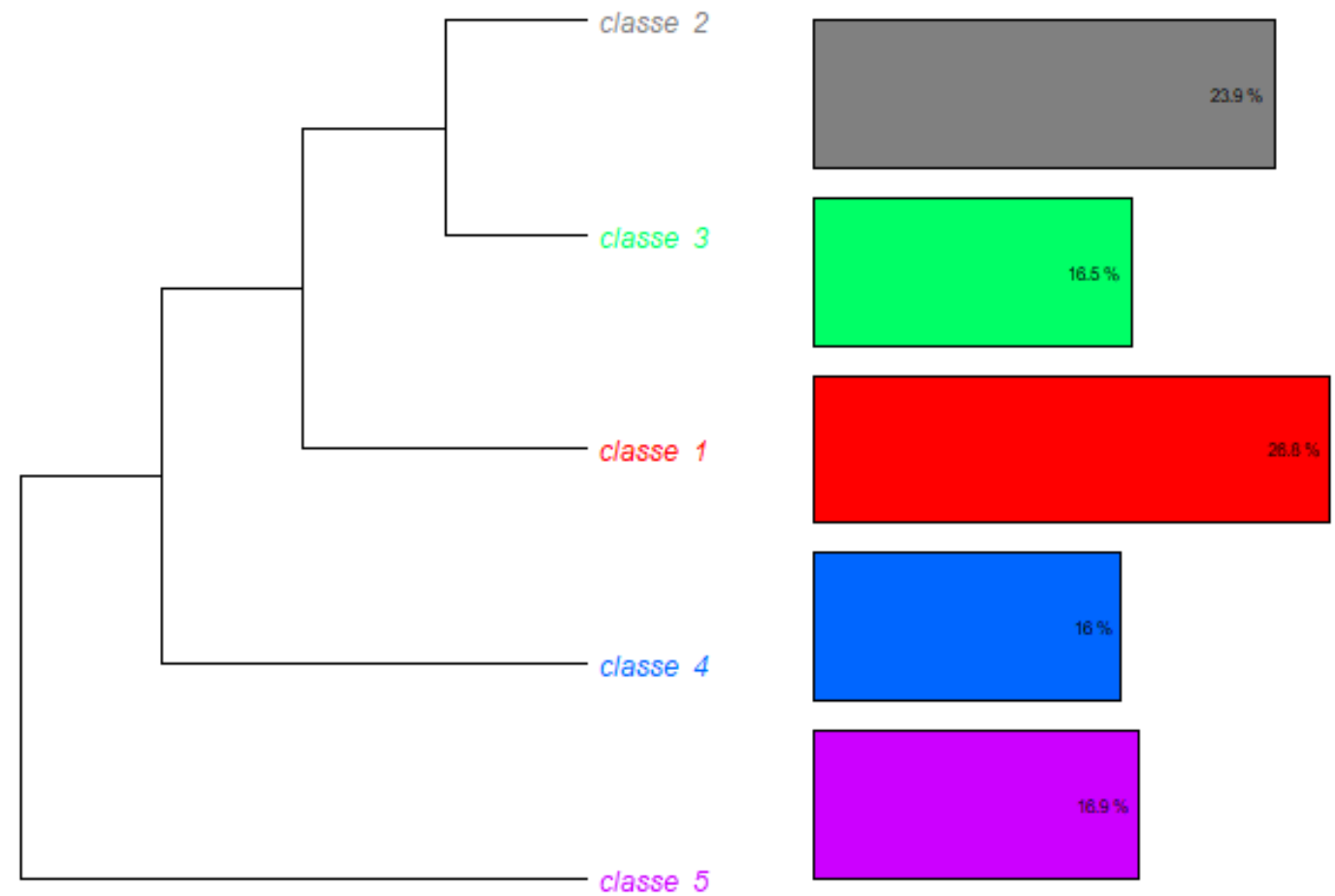

Figura 1. Dendrograma de classes - etapas do processamento Figura fornecida pelo software Iramuteq
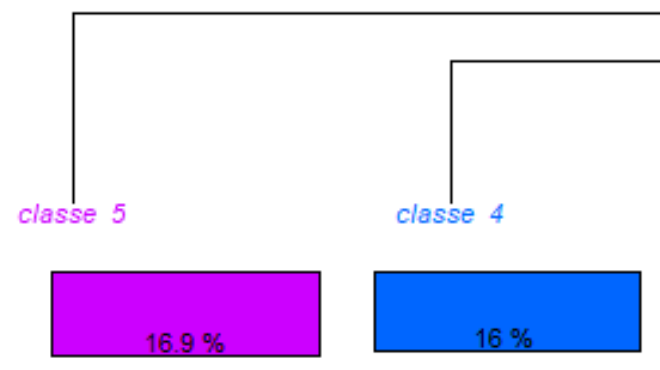

\section{petrobras \\ empresa}

terceirizadas

peăo

petroleiro

funcionário

diferença

dono

concursados

divisăo

petróleo

concurso

mandar

odebrecht

prestar

palavra

br

pejorativo

existir

igual

chamar

cliente

tratar

chamado

tratamento

contrato

hora
enfermeiro
médico
aeronave
minuto
desembarque
briefing
embarque
chegar
aeroporto
aguardar
noite
voo
helicóptero
banho
manhä
enfermaria
processo
ar_condicionado
depois
tomar
técnico_de_enfermagem
antecedència
unidade
seguinte
turno
ocorrer
sntrn

\section{terra}

acidente

questão

folga

vantagem

gosto

distância

trabalhar

beneficio

atividade

mudar

trabalho

como

perigoso

motivo

emprego

principal

financeiro

especificar

risco

gerar

tender

bastante

alto
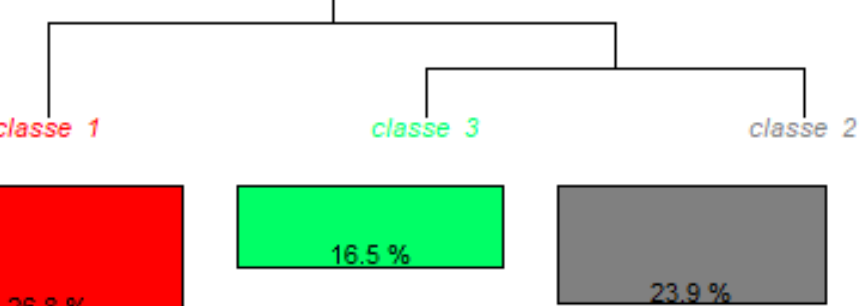

bom

casa

conhecer

às vezes

colega

mulher

conversar

vez

cerveja

aguentar

aprender

preciso

a_gente

pior

cansativo

entender

agradar

plataforma fixa

educação

ciúme

ligação

dia

homem

all

estranho

sinceramente

familia

falta

sentir

querer

procurar

aproveitar

esposo

quando

șair

junto

conflito

tempo

pai

acabar

saudade

legal

ritmo

deus

além

enfim

churrasco

presença

filho

Figura 2. Dendrograma de classes - com vocabulário

Figura fornecida pelo software Iramuteq 
Como se pode notar, as classes 1,2 e 3 formam um subconjunto que foi denominado "O contexto do trabalho offshore: vantagens, desvantagens e impactos". A classe 1, denominada "Vantagens e compensações do trabalho offshore", exibe um conteúdo lexical que interpreta-se como referente aos motivos que levaram os participantes a escolherem e/ou manterem-se no trabalho offshore. As palavras trabalhar, terra, folga, questão, atividade, vantagem, gosto, algumas das mais frequentes nesta classe, remetem à ideia de que é um trabalho que compensa, que tem vantagens em Quadro 1

Classe 1 - Vantagens e compensações do trabalho offshore

\begin{tabular}{ccccc}
\hline Palavra & $\begin{array}{c}\text { Frequência na } \\
\text { classe }\end{array}$ & $\begin{array}{c}\text { Frequência no } \\
\text { corpus }\end{array}$ & $\mathbf{\%}$ & $\mathbf{X}^{\mathbf{2}}$ \\
\hline terra & 58 & 113 & 51.33 & 39.31 \\
acidente & 18 & 21 & 65.71 & 38.03 \\
questão & 28 & 41 & 52.69 & 37.63 \\
folga & 49 & 93 & 76.92 & 35.22 \\
vantagem & 20 & 26 & 76.0 & 34.26 \\
gosto & 19 & 25 & 92.31 & 28.86 \\
distância & 12 & 13 & 91.67 & 26.09 \\
benefício & 11 & 12 & 59.09 & 24.55 \\
atividade & 26 & 44 & 75.0 & 24.22 \\
mudar & 15 & 20 & 39.21 & 23.35 \\
trabalhar & 89 & 227 & 42.76 & 22.21 \\
como & 62 & 145 & 90.0 & 20.6 \\
perigoso & 9 & 10 & &
\end{tabular}

Para ilustrar os conteúdos desta classe e auxiliar na sua compreensão, também são apresentados alguns segmentos de texto a seguir:

A principal vantagem é o financeiro $e$ essa questão do período que você tem de folga para planejar viagem $e$ quando... eu peguei muito essa fase quando eu estava mais jovem, era solteiro, antes de casar (part_02; sex_masc; petrobrás; aposentado)

Eles gostam, sabem que é bom para mim, os benefícios e salário os ajudam também, e eles sabem que se eu estivesse em terra trabalharia muito e não seria tão bacana nem poderia ajudar eles como eu faço hoje (part_10; sex_masc; terceirizada; ativo) relação ao trabalho em terra, por isso os entrevistados não pensam em mudança. Apesar disso, também estão presentes palavras como acidentes, perigoso, o que indica que é um trabalho que envolve riscos a serem enfrentados.

O quadro a seguir (Quadro 1) apresenta informações mais detalhadas sobre o conteúdo lexical dessa classe, apresentando a frequência, o índice de associação da palavra à classe $\left(\mathrm{X}^{2}\right)$, entre outras informações. 
trabalhar (part_18; sex_masc; terceirizada; ativo)

Dá medo, aquele lugar cheio de ferro, você tem que andar cheio de equipamento de segurança, é muito perigoso (part_25; sex_masc; petrobrás; aposentado)

O confinamento, a folga e a distância acho que o confinamento envolve muito essa questão da distância, e de você ficar fora por um tempo, sumir da vida das pessoas, das atividades, você

Quadro 2

não está disponível (part_01; sex_masc; petrobrás; ativo)

A classe 2, nomeada "Impactos na vida familiar e conciliações possíveis", encontra-se ligada a classe 3 , formando um subgrupamento denominado "Trabalho offshore $\mathrm{x}$ vida familiar/social". Tal classe reuniu $23,9 \%$ do corpus analisado, e as palavras com maior frequência (família, casa, quando, querer, tempo, falta, sentir) parecem indicam como os trabalhadores tentam conciliar o trabalho com a vida familiar, destacando-se a ausência que sentem e a busca de compensar o tempo perdido.

Classe 2 - Impactos na vida familiar e conciliações possíveis

\begin{tabular}{ccccc}
\hline Palavra & $\begin{array}{c}\text { Frequência na } \\
\text { classe }\end{array}$ & $\begin{array}{c}\text { Frequência no } \\
\text { corpus }\end{array}$ & $\mathbf{\%}$ & $\mathbf{X}^{\mathbf{2}}$ \\
\hline casa & 54 & 75 & 72.0 & 103.44 \\
família & 73 & 130 & 56.15 & 85.91 \\
falta & 34 & 42 & 80.95 & 78.6 \\
sentir & 31 & 43 & 72.09 & 57.48 \\
querer & 36 & 59 & 61.02 & 47.61 \\
procurar & 22 & 28 & 78.57 & 45.11 \\
aproveitar & 18 & 21 & 85.71 & 38.18 \\
esposo & 25 & 38 & 65.79 & 36.78 \\
quando & 70 & 166 & 42.17 & 33.53 \\
sair & 24 & 38 & 63.16 & 30.2 \\
junto & 18 & 26 & 69.23 & 25.69 \\
conflito & 8 & 8 & 100.0 & 25.63 \\
tempo & 40 & 87 & 45.98 & \\
\hline
\end{tabular}

Alguns segmentos de texto representativos dessa classe são apresentados a seguir:

O primeiro dia de trabalho era assim, você não chegava com a cabeça muito boa porque você saía da sua casa largando a sua família para ir para a plataforma (part_03; sex_masc; terceirizada; aposentado)

Acho que interferiu porque chegou mais no final eu já estava me sentindo estressado em embarcar pelo fato de você repetir a mesma coisa, você sair de casa, você embarcar, você ficar na plataforma os 14 dias (part_03; sex_masc; terceirizada; aposentado)
Então, assim, procuro viajar, se tiver o tempo tranquilo eu procuro viajar, eu procuro aproveitar ao máximo do momento que eu estou com minha esposa e sei que, se deus quiser, mais para frente, no futuro, vai vir filhos (part_05; sex_masc; petrobras, ativo)

Eu procuro estar bem, eu acho que, assim, a partir do momento que eu tenho que embarcar para conseguir o meu sustento eu sei que quando eu desembarcar eu tenho que estar aqui 100 por cento na minha casa (part_05; sex_masc; petrobras, ativo)

Então, por termos decidido juntos, eu posso dizer que hoje não tenho problemas com meu trabalho e minha família, vivo intensamente os dias que 
estou aqui junto com minha família, é $o$ que eu posso fazer tento estar próximo em tudo (part_09; sex_masc; terceirizada, ativo)

Eu fui criado dentro de uma família muito grande e por isso tenho uma dependência de estar perto da minha família, o que eu sinto mais falta é da presença da minha família (part_09; sex_masc; terceirizada, ativo)

Dos seus amigos, diante das pessoas que você ama, das suas atividades em terra, então é um estilo_de_vida totalmente diferente, eu acho que é um estilo_de_vida (part_01; sex_masc; petrobras, ativo)

Na questão social, é uma coisa que eu vejo muito, as pessoas tentando, e que aconteceu comigo também, as pessoas, quando em terra, tentam compensar um tempo perdido buscar fazer tudo ao mesmo tempo para que aquele tempo que você passou embarcado seja compensado de alguma forma (part_08; sex_masc; petrobras, aposentado)

A classe $3(16,5 \%)$, denominada "Relações no trabalho e impactos na vida familiar", parece tratar das relações interpessoais que se dão no contexto do trabalho (relação com colegas), que parecem ser positivas, mas também ressalta as mudanças que se dão em decorrência desse tipo de trabalho, o que acaba gerando, muitas vezes, problemas na vida familiar e conjugal. Bom, a_gente, às_vezes, colega, conhecer, entender, conversar, entre outras, são algumas das palavras com maior frequência na classe e ajudam a explicitar seu conteúdo.

Quadro 3

Classe 3 - Relações no trabalho e impactos na vida familiar

\begin{tabular}{|c|c|c|c|c|}
\hline Palavra & $\begin{array}{c}\text { Frequência na } \\
\text { classe }\end{array}$ & $\begin{array}{c}\text { Frequência no } \\
\text { corpus }\end{array}$ & $\%$ & $\mathbf{X}^{2}$ \\
\hline bom & 37 & 78 & 47.44 & 59.06 \\
\hline conhecer & 15 & 21 & 71.43 & 47.09 \\
\hline às_vezes & 29 & 62 & 46.77 & 44.17 \\
\hline colega & 20 & 39 & 51.28 & 35.76 \\
\hline mulher & 9 & 11 & 81.82 & 34.51 \\
\hline conversar & 10 & 14 & 71.43 & 31.17 \\
\hline vez & 19 & 40 & 47.5 & 29.17 \\
\hline cerveja & 5 & 5 & 100.0 & 25.47 \\
\hline aguentar & 5 & 5 & 100.0 & 25.47 \\
\hline aprender & 6 & 7 & 85.71 & 24.56 \\
\hline preciso & 6 & 7 & 85.71 & 24.56 \\
\hline a_gente & 32 & 94 & 34.04 & 23.33 \\
\hline pior & 10 & 17 & 58.82 & 22.54 \\
\hline
\end{tabular}

Para favorecer a melhor compreensão da classe, também são apresentados alguns trechos:

Então, a_gente passa aprender a viver ali sozinho, ainda mais eu que ia para plataforma que não conhecia ninguém, você está sozinho no meio de mais de 100 pessoas, você está sozinho (part_07; sex_masc; petrobras; aposentado)

A mulher, às_vezes, me chama a atenção, diz poxa parece que você não liga de estar aqui com a família. Não é que eu não ligue, eu me acostumei, eu me habituei a isso (part_07; sex_masc; petrobras; aposentado)

Então, o lazer o divertimento é muito bom, muito bom o lazer a bordo, muito boa muito boa a relação com os meus colegas é muito boa, é um funcionário se comunicando com o outro, dando apoio ao outro (part_19; sex_masc; terceirizada; aposentado) 
Então, eu não tenho colegas de trabalho, eu convivo com outras pessoas que eu passo a conhecer naquele embarque, nada garante que eu vou embarcar com a mesma equipe, isso é raridade (part_23; sex_masc; petrobras, ativo)

É bom, minha relação com os colegas de trabalho é muito boa, muito boa, agora sim, há 10 anos na mesma plataforma, sim (part_04; sex_masc; petrobras, ativo)

Só às_vezes surge uma diferença entre os colegas, um gosta de fazer uma coisa e não outra, e acaba dificultando, mas eu me dou bem com todos eles (part_24; sex_masc; petrobras, ativo)

É sim, mas ela só é afetada pelo lado ruim se eu deixar... eu tenho um monte de colegas que são, vamos dizer assim, 80 por cento dos homens que trabalham embarcados tem problemas familiares sérios (part_09; sex_masc; terceirizada, ativo)
Interfere, isso é lógico, a maioria dos aposentados é divorciado porque... por causa do embarque, às_vezes a mulher não aguenta essa vida, às_vezes o embarcado volta do embarque e desconfia da mulher (part_25; sex_masc; petrobrás, aposentado)

A classe $4(16 \%)$ foi nomeada "Rotina/dinâmica de trabalho na plataforma", e reúne um conjunto de termos que indicam como tema principal a rotina de trabalho na plataforma, fazendo referências aos procedimentos de embarque, à chegada na plataforma após a folga, ao primeiro dia do novo turno de trabalho, às questões relativas a turno de trabalho, os recursos a bordo (como equipe médica), entre outras. São exemplos de palavras com alta frequência nessa classe: hora, chegar, embarque, médico, desembarque, aeronave, voo, geralmente, aeronave, enfermeiro, entre outras.

Quadro 4

Classe 4 - Rotina/dinâmica de trabalho na plataforma

\begin{tabular}{ccccc}
\hline Palavra & $\begin{array}{c}\text { Frequência na } \\
\text { classe }\end{array}$ & $\begin{array}{c}\text { Frequência no } \\
\text { corpus }\end{array}$ & $\mathbf{\%}$ & $\mathbf{X}^{\mathbf{2}}$ \\
\hline hora & 47 & 69 & 68.12 & 150.6 \\
enfermeiro & 17 & 19 & 89.47 & 78.06 \\
médico & 22 & 32 & 68.75 & 68.73 \\
aeronave & 15 & 17 & 88.24 & 51.91 \\
minuto & 11 & 12 & 91.67 & 50.46 \\
desembarque & 16 & 23 & 69.57 & 47.82 \\
briefing & 9 & 9 & 100.0 & 47.7 \\
embarque & 27 & 55 & 49.09 & 46.46 \\
chegar & 35 & 83 & 42.17 & 46.29 \\
aeroporto & 11 & 13 & 84.62 & 37.12 \\
aguardar & 7 & 7 & 100.0 & 35.15 \\
noite & 12 & 18 & 66.67 & 33.79 \\
voo & 11 & 16 & 68.75 & \\
\hline
\end{tabular}

Os segmentos de texto que se seguem ilustram o contexto em que essas palavras apareceram e subsidiam as interpretações sobre a classe.
É prazeroso o que eu faço, mas o ruim é ficar 14 dias longe de casa, o que diferencia é que você não precisa pegar ônibus, você acordou já está no seu trabalho, a hora do almoço você saiu da sua sala já entra na cozinha 
para almoçar (part_04, sex_masc, petrobras, ativo)

O inconveniente é que você fica na plataforma 24 horas, e você só ganha 12 horas, no meu caso eu vou dormir e a qualquer hora os superiores me chamam (part_04, sex_masc, petrobras, ativo)

Você está se adaptando ainda no local de trabalho, você custa a engrenar sua mente, depois você começa a tomar ciência das coisas, a ficar mais relaxado, tem enfermaria, tem médico, tem enfermeiro 24 horas para atender (part_04, sex_masc, petrobras, ativo)

Mas eu entro 7 horas no turno, fico vendo o que aconteceu no turno anterior, dou uma atualizada do que ocorreu, vou na discussão diária de segurança com o pessoal da operação da sala de controle (part_14, sex_fem, terceirizada, ativo)

Aguardo, vai ser anunciado à Quadro 5 chamada para o embarque para plataforma, depois faço o briefing de embarque, onde é apresentado sobre a segurança do voo, o tipo de aeronave, quanto tempo vai levar, e onde estão os coletes salva vidas (part_22, sex_masc, terceirizada, ativo)

Para o desembarque é o mesmo processo, tenho uma data fixa e só não desembarco se ocorrer algum imprevisto. Fora isso aguardo a aeronave para voltar à terra. na plataforma geralmente nós embarcados temos a academia, lugares com televisão e internet, e é basicamente isso (part_23, sex_masc, petrobras, ativo)

A situação de você ter que entrar uma aeronave e enfrentar cerca de 50 minutos a 1 hora de voo com, muitas vezes chuva forte, vento forte, tempo ruim, isso, essa tensão pré embarque é muito maior do que depois quando você já está na plataforma (part_09, sex_masc, terceirizada, aposentado)

Classe 5 - Relações intergrupais

\begin{tabular}{|c|c|c|c|c|}
\hline Palavra & $\begin{array}{c}\text { Frequência na } \\
\text { classe }\end{array}$ & $\begin{array}{c}\text { Frequência no } \\
\text { corpus }\end{array}$ & $\%$ & $\mathbf{X}^{2}$ \\
\hline petrobras & 117 & 135 & 86.67 & 543.86 \\
\hline empresa & 90 & 112 & 80.36 & 363.3 \\
\hline terceirizadas & 63 & 66 & 95.45 & 311.38 \\
\hline peão & 21 & 22 & 95.45 & 98.98 \\
\hline petroleiro & 20 & 21 & 95.24 & 93.86 \\
\hline funcionário & 38 & 77 & 49.35 & 62.78 \\
\hline diferença & 17 & 27 & 62.96 & 42.0 \\
\hline dono & 8 & 8 & 100.0 & 39.69 \\
\hline concursados & 7 & 7 & 100.0 & 34.7 \\
\hline divisão & 7 & 7 & 100.0 & 34.7 \\
\hline peroba & 6 & 6 & 100.0 & 29.71 \\
\hline petróleo & 12 & 19 & 63.16 & 29.55 \\
\hline concurso & 7 & 8 & 87.5 & 28.65 \\
\hline mandar & 9 & 13 & 69.23 & 25.72 \\
\hline odebrecht & 5 & 5 & 100.0 & 24.73 \\
\hline
\end{tabular}

Separada das demais classes está a classe 5, intitulada, "Relações intergrupais", abordando as relações, que incluem diferenças e assimetrias, entre os trabalhadores que são funcionários da Petrobrás e os que são contratados de empresas terceirizadas. $\mathrm{O}$ universo temático que caracteriza a classe, portanto, trata da natureza e implicações do vínculo trabalhista (diferenças salariais, de tratamento, etc.) e das relações intergrupais decorrentes dessas diferenças. As palavras destacadas no dendrograma da Figura 1 em 
termos de frequência, tais como petrobras, empresa, terceirizados, funcionário, peão, petroleiro, diferença, dentre outras, são sugestivas quanto à natureza das relações A seguir são apresentados alguns segmentos desta classe:

Eu sendo da petrobras tem mais chance do funcionário me deixar tentar entrar, por_exemplo, se precisar priorizar, ah está dando problema em uma lavagem de macacão, vou priorizar a empresa petrobras, eu sou da petrobras (part_01, sex_masc, Petrobrás, ativo)

Te tratam de uma forma que parece que você também é da petrobras, então eu não tenho do que reclamar (part_06, sex_fem, terceirizada, ativo)

Mas se for assim, todos são peões, até os da petrobras, eu sou das terceirizadas, nós somos terceirizadas, é mão_de_obra direta, eu sou indireta, então mão_de_obra direta é quem executa o trabalho e indireta mantém as condições favoráveis para execução do trabalho (part_12, sex_masc, terceirizada, ativo)

Tem a questão do assédio moral também, que eu não sei se a pergunta foi nesse quesito, mas todo mundo é igual, ninguém é melhor do que ninguém porque trabalha na empresa petrobras ou na empresa que é dona da plataforma (part_18, sex_masc, terceirizada, ativo)

Eles são petrobras, funcionários da empresa petrobras, é peroba porque eles foram aprovados em um concurso (part_22, sex_masc, terceirizada, ativo)

Existe a diferença, sim, dos grupos, existem várias formas de você falar dos funcionários da petrobras, você chama da petrobras de br, tem um que é mais pejorativo, que as terceirizadas estabelecidas entre esses dois grupos, que se diferenciam pelo fato de serem ou não funcionários de uma grande empresa estatal.

falam que é peroba (part_14, sex_fem, terceirizada, ativo)

Se você tem um cargo mais alto na empresa você não é chamado de peão, só que eu tento sempre ir contra isso dizendo para eles que eu sou peão, $e$ quando estou em reunião com a petrobras não admito que desvalorizem meu pessoal (part_09, sex_masc, terceirizada, ativo)

Eles petroleiros, são pessoas que estudaram, passaram em um concurso, e hoje levam um título nas costas, mas não são melhores que nós porque a sociedade estabeleceu e o convívio nosso estabeleceu uma divisão que não temos como acabar agora (part_09, sex_masc, terceirizada, ativo)

Ainda que a petrobras tente, não é possível acabar com hábitos tão antigos de divisão dentro das plataformas (part_09, sex_masc, terceirizada, ativo)

\section{Discussão}

O intuito do estudo foi conhecer o saber construído acerca desse tipo de trabalho pelos participantes no confronto com a realidade vivida, identificando o sentido atribuído às suas vivências (as RS), o que foi possível a partir da análise dos dados resultantes do processamento das informações desenvolvido com o uso do IRAMUTEQ. A análise das classes acima referidas permite algumas considerações a respeito das RS de trabalho offshore para os participantes, suas vivências e sobre os impactos na vida familiar.

Cabe mencionar de início, como destacam Coutinho e Menandro (2009), que "as classes, além de apresentarem uma lista temática de palavras, apontam a construção 
dinâmica do discurso das pessoas que nos falam, e ao mesmo tempo, trazem indicações do sentido do que foi falado por elas" (p. 215). Sendo assim, as contradições, muitas vezes, identificadas nos discursos dos participantes são entendidas como conciliáveis, "até porque os discursos são marcados por ambiguidade" (p. 215).

Convém explicitar que, no contexto de realização da pesquisa - em região do norte fluminense onde está situado o maior polo brasileiro de plataformas marítimas e de produção de petróleo e gás - o trabalho offshore constitui atividade relevante e amplamente reconhecida, sendo sua caracterização objeto de conversas, reflexões e disseminação de opiniões e de ocorrências ouvidas a respeito do assunto. Tais processos envolvem tanto os diferentes trabalhadores do setor como outras pessoas que com eles têm contatos sociais por diferentes razões ou que com eles têm convivência familiar, de trabalho ou de amizade. É possível dizer que aqueles que atuam em tal regime têm tanto a vivência dessa modalidade de trabalho como o conhecimento de informações que circulam sobre o trabalho offshore nos ambientes em que estão inseridos, juntamente com informações que resultam de reflexões deles próprios sobre sua condição. Isso fica evidente, em vários pontos, nas próprias respostas dos participantes, como nos exemplos: "o confinamento envolve muito essa questão da distância, e de você ficar fora por um tempo, sumir da vida das pessoas, das atividades, você não está disponível”; "oitenta por cento dos homens que trabalham embarcados têm problemas familiares sérios"; "não é possível acabar com hábitos tão antigos de divisão dentro das plataformas". Em tal acepção entende-se que há necessidade de considerar relevante o desenvolvimento de uma "teorização" socialmente construída sobre essa modalidade de trabalho, no contexto em que foi investigada, que serve de base e justificativa para a ação dos sujeitos, sejam eles trabalhadores embarcados, trabalhadores que planejam atuar dessa forma, ou trabalhadores de quaisquer outros setores.
Como já foi apontado, a classe 1 é caracterizada por conteúdo relacionado aos motivos que levaram os participantes a escolherem e/ou a manterem-se no trabalho offshore. Mesmo com as dificuldades inerentes a esse tipo de trabalho, os entrevistados indicam compensações/vantagens, além de grande identificação com a atividade. O conteúdo dessa classe foi constituído pelo discurso tanto de trabalhadores que estão na ativa, quanto de aposentados, o que indica a permanência da ideia de que vale a pena se esforçar, "dar o sangue" para ficarem num emprego em que a segurança financeira, grande diferencial, parece compensar quaisquer dificuldades (trabalho noturno, confinamento, risco, entre outras), ao menos provisoriamente.

Esses resultados corroboram dados obtidos por Carvalho (2010) com trabalhadores marítimos embarcados, pois o retorno financeiro aparece como fator mantenedor e motivador nesse tipo de ocupação, considerada difícil, porém "adaptável". Segundo a autora, mesmo quando mencionam as dificuldades próprias do trabalho embarcado, enfatizam que não se arrependem da escolha dessa carreira e que é possível se "acostumar" às suas contingências. Para tais sujeitos, o que podem proporcionar aos familiares (por exemplo, educação de qualidade para os filhos) é a maior recompensa. "Em prol disto, muitos sacrificam sua saúde e convívio ampliado (parentes, amigos) ficando com a sensação do "dever cumprido", mesmo não acompanhando integralmente a formação dos filhos nem desfrutando cotidianamente da convivência familiar" (Carvalho, 2010, p. 61).

$\mathrm{Na}$ classe 2 evidenciam-se as dificuldades resultantes do afastamento da família e, ao mesmo tempo, as tentativas de conciliação e de compensação pelo "tempo perdido". Assim, o conteúdo predominante do que disseram girou em torno da falta sentida da família e dos amigos, das apreensões em relação aos familiares enquanto se está embarcado, e do sentimento de culpa pela ausência em eventos e situações importantes. 
Coelho e Paparelli (2010) também evidenciaram em estudo com trabalhadores offshore a presença de ansiedade e preocupação constante com a família durante o período de embarcação. Com isso, a comunicação com a família, atualmente facilitada por meio do telefone e da internet, caracterizou-se como necessidade constante no cotidiano dos participantes, o que nem sempre é bem compreendido por quem está fora daquele contexto. Segundo os autores, o trabalhador embarcado desenvolve necessidade de estabelecer contato com sua casa muitas vezes, ao ponto de fazer com que as pessoas próximas se sintam incomodadas com o excesso de ligações, que resulta em esvaziamento de conteúdo nas conversas. "O esvaziamento das conversas parece ser reflexo da redução das experiências vivenciada pelo trabalhador offshore, que está por quatorze dias limitado a um espaço físico e a relações formais" (Coelho \& Paparelli, 2010, p. 9). Os participantes também ressaltaram a falta de privacidade no momento das ligações, impondo limites em relação ao que poderia ser dito. Tal fato foi visto como agravante para que as conversas ficassem ainda mais "esvaziadas" e pouco interessantes (Coelho \& Paparelli, 2010).

A perda de eventos sociais e familiares também foi enfatizada no estudo de Coelho e Paparelli (2010). Tal fato, de acordo com os autores, "contribui para que a sensação de distanciamento fique ainda maior e a sensação de não-pertencimento muito presente" (p. 9). De forma similar, os resultados de Carvalho (2010) também indicam como principal dificuldade do trabalho embarcado a distância da família e das atividades sociais em terra, o que é gerador de angústia, principalmente pela impossibilidade de participação em eventos familiares e sociais, perdendo a oportunidade de um tipo de experiência que não é plenamente recuperável.

Além disso, Carvalho (2010) destaca que, segundo os participantes de seu estudo, o trabalho embarcado gera grande cansaço físico e mental, uma vez que, além de terem que cumprir as atividades exigidas em turnos desfavoráveis, precisam ainda administrar a ausência da família e da vida social, condições essas que constituem fator de estresse.

Considerando a classe 2 e 3 em conjunto (subgrupamento Trabalho offshore $x$ vida familiar e social), é possível notar as repercussões desse tipo de trabalho na vida pessoal desses trabalhadores. Como se nota na classe 3, o fato de ficarem por longos períodos nas plataformas faz com que desenvolvam vínculos de amizade que os ajudam a suportar a distância da família e da vida social, e ao mesmo tempo, produz um estreitamento de laços, que as vezes extrapolam o contexto de trabalho, o que nem sempre é compreendido pelos familiares. Com isso, surge a necessidade de mais uma conciliação.

Assim, o grande eixo constituído pelas classes 1,2 e 3 parece abordar as vantagens do trabalho embarcado e, ao mesmo tempo, as desvantagens e dificuldades, o que indica que, na forma como compreendem e vivenciam o trabalho embarcado para esses indivíduos estão presentes elementos contraditórios em princípio, mas, em verdade, reveladores da dinâmica das representações. Mesmo reconhecendo os custos/ônus do trabalho offshore, enfrentam as dificuldades valorizando os benefícios e compensações, e cultivando a esperança de que não será "para sempre". Neste sentido, é inegável a presença de ambiguidades na forma de compreensão do mesmo (pois existem ganhos e perdas), tal como apontou Castro (2013), em estudo sobre os processos psicológicos de petroleiros offshore no âmbito do trabalho embarcado. Por outro lado, é interessante perceber que muitos parecem apresentar imagem de si próprios positiva pelo fato de permanecerem neste tipo de trabalho, destacando que o mesmo "é para poucos", pois muitos não têm estrutura de suportar o confinamento e a rotina estressante das plataformas.

A classe 4 , que trata da dinâmica de trabalho em plataforma de petróleo e suas consequências (aspectos relativos aos procedimentos a serem cumpridos na rotina de trabalho - adaptação à escala/rotina, embarque e desembarque, troca de turno, voo para a 
plataforma, ritmo de trabalho, entre outras), se liga a esse eixo supracitado, formando um grande bloco cujo conteúdo, pensado em conjunto, contribui para a compreensão dos prováveis elementos que compõem a RS de trabalho offshore para os entrevistados, além de contribuírem para o entendimento de suas experiências e das implicações para a vida familiar e social.

$\mathrm{Na}$ realidade, mesmo na classe 4 , em que estão englobados procedimentos relacionados à rotina de atividades, os participantes parecem se referir aos riscos e interferências dessa rotina em suas vidas (consequências pessoais) e na de pessoas próximas. O cansaço aparece como uma consequência direta, assim como o estresse do embarque e desembarque. Castro, (2013) destaca que a percepção do tempo também fica alterada quando o trabalhador está dentro da plataforma, e fala de uma assimetria de tempo de trabalho e descanso/folga, o que leva o trabalhador a perceber o tempo na plataforma como um "tempo perdido", colocando-se em contagem regressiva para o desembarque. E complementa: "a percepção de uma assimetria entre os tempos de trabalhoembarcado/descanso-desembarcado (...) leva a consequências ainda mais graves. Principalmente porque não é só a cadência da vida que fica alterada, mas até a própria vida em si" (Castro, 2013, p. 841).

Em relação à dinâmica embarque desembarque, Clemente (2013) ressalta que as condições de risco iminente que caracterizam o embarque são, por si só, geradoras de estresse e angústia. $\mathrm{Na}$ verdade, segundo a autora, os dias que antecedem o embarque são sempre dias de desconforto para os trabalhadores. Leite (2009) assinala algumas condições e reações presentes no pré-embarque:

A ambiguidade entre sofrimento e prazer, gerada pela iminência do rompimento de laços de afetividade, de amizade, conjugais, de companheirismo, etc., que o trabalhador deixa em terra; a irritabilidade, distúrbios do sono, a culpa, a quietude, o isolamento, a depressão, são alguns dos sinais que, periodicamente, dominam o trabalhador e as pessoas que estão a sua volta nesse período" (p. 118)

Carvalho (2010) também observou essa tensão do pré-embarque como item dos resultados que obteve. Destaca que esse é fator que afeta emocionalmente os participantes em seus últimos dias de folga, comprometendo a qualidade do tempo em terra nesse período. A esse respeito, Farias (2008), com base nos resultados de seu estudo, destaca: "um ou dois dias antes do embarque, começa uma série de 'sintomas' que incluem insônia, mau humor, mudez, inquietude, indisposição para qualquer atividade, dor de cabeça e de barriga (...) A inapetência para o sexo não é incomum" (p. 7). Não menos estressante é o desembarque, que nem sempre significa o retorno imediato para casa e para a família. Muitos trabalhadores residem em lugares distantes da cidade em que desembarcam, o que faz com que aqueles que não podem ir diretamente para suas cidades de origem, fiquem em pousadas e hotéis, postergando ainda mais o retorno para o lar (Clemente, 2013).

Coelho e Paparelli (2010) destacam que, mesmo no período em que estão com suas famílias, desembarcados, os trabalhadores offshore, muitas vezes, enfrentam outro tipo de isolamento. Isso ocorre porque, geralmente, as pessoas em seu entorno compartilham outro ritmo de trabalho e não estão de folga, o que faz com que permaneçam sozinhos por longo período. Além disso, há o fato de que muitos não conseguem organizar adequadamente o tempo quando estão desembarcados, apresentando uma espécie de tentativa permanente de recuperar o tempo despendido na plataforma.

Salles e Costa (2013) apontam que o trabalho em ambiente de confinamento pode levar ao rompimento entre as diversas esferas da vida. Com base nos resultados de seu estudo destacam: 
o confinamento é sugerido como um regime de trabalho que ocasiona uma mudança na rotina da vida social do indivíduo, pois ele se estende, em alguns casos, para a vida fora daquele ambiente. Há uma espécie de desajustamento ao mundo "além" espaço confinado, uma vez que o trabalhador transita, em última instância, entre dois espaços com códigos, lógicas, posturas e atitudes que, na prática, pouco se comunicam. A dificuldade da transição entre esses dois mundos e a carga psicológica que essa transição impõe é revelada quando os entrevistados destacam que, dias antes de embarcar, já começam a "pensar como no trabalho". (Salles \& Costa, 2013, p. 237).

A classe 5 reuniu elementos textuais que fazem referência, especificamente, à questão das diferenças entre os trabalhadores das plataformas que resultam de serem eles funcionários da empresa estatal Petrobrás ou de empresas terceirizadas (caracterizando uma situação ilustrativa de evidentes diferenças intergrupais). Muitos participantes, de início, disseram não haver diferenças de tratamento e relacionamento entre trabalhadores pelo fato de representarem empresas diferentes. Contudo, a maioria dos entrevistados, em momentos posteriores, admitiu haver muitas diferenças, mencionando a existência de hierarquia informal entre "petroleiros" (da Petrobrás) e "peões" (de empresas terceirizadas), do que resulta desvalorização, desrespeito e inobservância de direitos. Um dos argumentos justificadores da citada hierarquia é o fato dos servidores da Petrobrás terem prestado concurso para estarem onde estão.

Estudo de Pena (2002) também destaca a relação hierárquica entre petroleiros (Petrobrás) e contratados (serviços terceirizados), o que acaba levando ao convívio conturbado. Tal questão, segundo a autora, decorre da diferenciação estabelecida entre aqueles que prestaram concurso público e aqueles que fazem parte de equipe de empresa privada. Farias (2008), de forma similar, constatou uma "hierarquia intrincada" entre estes grupos em seu estudo. Seus resultados revelaram forte divisão entre os funcionários da Petrobrás e os das empresas terceirizadas, numa relação assimétrica, de modo que "os primeiros se consideram em situação vantajosa em relação ao segundo grupo, sendo por sua vez encarados de forma crítica pelos empregados terceirizados" (p. 9). E continua:

a estabilidade, a boa remuneração e a experiência do serviço nas plataformas servem mais uma vez como base para a desconfiança que nutrem os 'Petrobrás' - que se afirmam como os únicos 'verdadeiros petroleiros' - em relação aos empregados de outras firmas. Estes são vistos como ignorantes da realidade do trabalho em alto mar, sem conexão afetiva com a atividade - algo que estrutura a identidade dos homens da Petrobrás, como vimos. Enquanto isso, os "Petrobrás" são vistos como arrogantes, discriminadores e, pelos mais escolarizados, como ignorantes da realidade do mercado do trabalho ("eles só sabem aquilo ali, mais nada") (p. 9).

Destaca-se ainda, tal como observado por Menezes Gomes (2002, citada por Farias 2008) em seu estudo sobre trabalhadores terceirizados, que alguns participantes mencionaram que entre os próprios trabalhadores terceirizados existe uma hierarquia: funcionários menos qualificados e que exercem atividades braçais, por alguns chamados de peões, e os que são empregados especializados, e por isso, situam-se em patamar superior aos demais.

Consideradas todas essas questões, pode-se dizer que a classe 5 explicita o funcionamento hierárquico presente no interior das plataformas. Tal funcionamento, como mostra Farias (2008), está assentado em dicotomias e na relação hierárquica existente entre as próprias empresas. Dessa forma, percebe-se uma mistura entre a lógica dos 
funcionários e a lógica empresarial, "onde os 'méritos' e 'deméritos' podem significar posições acima ou abaixo no status de cada indivíduo, na sua posição no trabalho e na escala salarial"' (p. 14).

Apesar de não ter sido objetivo do presente estudo formular articulação da TRS com a teoria da Identidade Social, de H. Tajfel (1982; 1983), percebeu-se, a partir dos resultados, que tal proposta muito enriqueceria a análise, valendo como sugestão para novos estudos com esse grupo de trabalhadores. De todo modo, é possível ressaltar aqui a função identitária das RS, uma vez que atuam como um sistema de referência para as práticas sociais e produção de identidades, interferindo no modo como se processam as interações entre indivíduos e grupos (Jodelet, 2001). Os processos identitários, segundo Deschamps e Moliner (2009), possibilitam aos sujeitos "elaborar e manter conhecimentos a propósito deles mesmos e de outrem, dos diferentes grupos aos quais eles pertencem e com os quais eles estão em interação" (p. 81), contribuindo para a definição de RS e sendo por elas definidos.

Vale observar que, de forma geral, o discurso das entrevistadas mulheres não alcançou destaque nas classes, o que pode estar relacionado com o número pouco expressivo de participantes em comparação com o número de participantes do sexo masculino. A dificuldade, já mencionada, de abarcar participantes do sexo feminino na pesquisa, por si só, já explicita a questão do trabalho embarcado ser considerado "de homem". Isso, possivelmente, tem relação com o fato de que, mesmo com as diversas mudanças processadas ao longo das últimas décadas em relação à mulher e seu papel na sociedade, ainda existe maior associação dela com determinados tipos de funções, consideradas mais adequadas ao público feminino, bem como sua exclusão de tarefas que exigem risco e perigo. A esse respeito Carvalho (2010, p. 59) ressalta:

Não se questiona tanto esse tipo de trabalho sendo desempenhado por homens porque parece ser mais aceitável que estes possam ficar distantes de suas famílias. Podemos dizer que é mais aceitável socialmente que os homens não tenham obrigação com a família. Portanto, isso acaba sendo um reflexo dessa cisão de gênero. Quando se trata de uma mulher, é como se ela evidenciasse "o problema", o que não deve ocorrer. Ficaria a cargo dela a responsabilidade da criação de seus filhos.

Isso também pode ajudar a explicar o fato de que a maioria das mulheres participantes não tinha, na época da entrevista, relacionamento fixo e filhos (apenas uma entre as quatro estava casada e outra tinha filho). Contudo, o número reduzido de participantes do sexo feminino impede a generalização desses resultados, além de não corresponder aos objetivos da pesquisa. De toda forma, seriam interessantes novos estudos que se ocupassem dessa questão em específico.

Fazendo uma articulação mais explícita com a teoria de base do estudo, a TRS, e considerando o objetivo geral da pesquisa, pode-se dizer que, tomados em conjunto, os resultados evidenciam elementos que indicam tanto as significações dos participantes sobre o trabalho offshore, ou seja, elementos de RS, quanto informações sobre suas vivencias práticas nesse contexto específico de trabalho. Fica claro que há uma partilha da compreensão de que esse tipo de trabalho, mesmo com evidentes desvantagens (impactos negativos na vida familiar, rotina estressante, entre outras), "vale a pena" ser mantido, pois há compensações maiores, e são essas significações que possibilitam aos trabalhadores orientarem-se e permanecerem neste trabalho. Assim, identifica-se uma relação de interdependência entre as representações e as práticas sociais.

\section{Considerações finais}

Os resultados das classes entendidos em conjunto ajudam a perceber que, para os entrevistados, as significações/representações e experiências em relação ao trabalho offshore 
estão marcadas por elementos como: as vantagens que justificam a escolha $\mathrm{e}$ permanência no trabalho embarcado (estabilidade financeira, folga, segurança material para a família); as dificuldades decorrentes do tipo de trabalho (falta sentida dos familiares e amigos; preocupações com a família durante o período de embarque; ausência em eventos familiares/sociais importantes); os aspectos relacionados a dinâmica de trabalho nas plataformas (tensões relativas ao embarque e desembarque; cansaço e estresse relacionados à rotina de trabalho; condições de insalubridade e situações de riscos); as diferenças decorrentes da empresa com a qual possuem vínculo (Petrobrás ou empresa privada).

Os resultados aqui apresentados corroboram dados obtidos em pesquisas anteriores, a maioria datando da primeira década dos anos 2000, que indicam o retorno financeiro e as folgas em terra com duração mínima de quatorze dias como os principais fatores mantenedores e motivadores nesse tipo de ocupação. Os entrevistados percebem que seu trabalho se desenvolve em contexto considerado difícil, daí decorrendo um quadro de sofrimento, entendido como necessário, mas com o qual é possível lidar e acostumar-se, ao menos por certo período. Os dados acerca das desvantagens também se apresentam em conformidade com estudos precedentes, destacando-se os aspectos relacionados ao confinamento, à distância da família e das atividades sociais, e à impossibilidade de recuperar os momentos "perdidos".

Os resultados do presente estudo foram obtidos com número reduzido de participantes contatados a partir de critérios que não incluem aleatoriedade, o que limita sua representatividade. De toda forma, constituem indicativos de interesse heurístico acerca das questões envolvidas no cotidiano do trabalho offshore. Novos estudos são necessários para ampliar o alcance dos dados em termos de generalização e para contribuir para conjugação saudável entre esse tipo de trabalho e a vida familiar/social, inclusive com sujeitos que não desenvolvam atividades no contexto offshore.

\section{Referências}

Abric, J. C. (2000). A abordagem estrutural das representações sociais. In A. S. P. Moreira \& Oliveira, D. C. (Orgs.), Estudos interdisciplinares em representação social (pp. 39-46), Goiânia, GO: AB.

Camargo, B. V., \& Justo, A.M. (2013a). IRAMUTEQ: Um Software Gratuito para Análise de Dados Textuais. Temas em Psicologia, 21 (2), 513-518. doi:10.9788/TP2013.2-16

Camargo, B. V., \& Justo, A. M. (2013b). Tutorial para uso do software Iramuteq. Recuperado de http://www.laccos.com.br.

Carvalho, M. M. (2010). Vida e trabalho de marítimos embarcados do setor offshore (Dissertação de Mestrado). Escola Nacional de Saúde Pública/ENSP. Rio de Janeiro, RJ: Fiocruz.

Castro, A. C. (2013). Produção offshore na Bacia de Campos (RJ): a perspectiva da
Psicologia do Trabalho. Gestão e

Produção, São Carlos, 20 (4), 833-846.

Castro, A. C., Nunes, D. K. P. (2008) Ações e relações entre Gestão do Conhecimento e estresse do petroleiro offshore. In Congresso Nacional de Excelência em Gestão - CNEG, 4. Niterói, São Paulo.

Chaves, A. M., \& Silva, P. L. (2011).

Representações sociais. In L. Camino, A. R. R. Torres, M. E. O. Lima e M. E. Pereira (Orgs.), Psicologia Social: temas e teorias (pp. 299-349). Brasília, DF: TechnoPolitik.

Clemente, C. C. (2013). Trabalho offshore: deslocamentos, afetos e usos do tempo. In Anais do Seminário Internacional Fazendo Gênero 10 (1-6), Florianópolis, SC.

Coelho, L. L. V., \& Paparelli, R. (2010). A experiência do trabalhador offshore: o caso de operadores de ROV. In Resumos do VII Seminário de Saúde do Trabalhador e $V$ Seminário O Trabalho em Debate "Saúde 
Mental Relacionada ao Trabalho". Franca, São Paulo.

Coutinho, S. M. S., \& Menandro, P. R. M. (2009). A dona de tudo: um estudo intergeracional sobre representações sociais de mãe e esposa. Vitória, ES: GM Editora.

Deschamps, J-C, \& Moliner, P. (2009). A identidade em Psicologia Social. Petrópolis: Vozes.

Duveen, G. (2003). Introdução: O poder das ideias. In S. Moscovici. Representações sociais: Investigações em Psicologia Social (pp. 7-28). Petrópolis, RJ: Vozes.

Farias, P. S. (2008). Mulheres ao mar: gênero, cor e sociabilidade entre trabalhadores de plataformas marítimas em Campos, RJ. In Anais da $26^{a}$ Reunião Brasileira de Antropologia - Desigualdade na diversidade, Porto Seguro, Bahia.

Freitas, C. M., Souza, C. A. V, Machado, J. M. H., \& Porto, M. F. S. (2001). Acidentes de trabalho em plataformas de petróleo da Bacia de Campos. Cadernos de Saúde Pública, 17 (1), 117- 130.

Houaiss, A., \& Villar, M. S. (2001). Dicionário Houaiss da língua portuguesa. Rio de Janeiro, RJ: Objetiva.

Jodelet, D. (2001). Representações sociais: Um domínio em expansão. In D. Jodelet (Org.) As representações sociais (pp.1744). Rio de Janeiro, RJ: EdUERJ.

Leite, R. M. S. C. (2009). Bandeirantes do mar: identidade dos trabalhadores das plataformas. Niterói, RJ: Intertexto.

Martins, S. M. R. (2007). O trabalho offshore: um estudo sobre as repercussões do confinamento nos trabalhadores das plataformas de petróleo na Bacia de Campos, RJ (Dissertação de Mestrado). Programa de Pós-Graduação em Políticas Sociais do Centro de Ciências do Homem. Universidade Estadual do Norte Fluminense.
Moscovici, S. (1961/2012). A psicanálise sua imagem e seu público. Tradução: $\mathrm{S}$. Fuhrmann - Petrópolis, RJ: Vozes.

Moscovici, S. (2003). Representações sociais: Investigações em Psicologia Social. Petrópolis, RJ: Vozes.

Pena, A. C. (2002). Relato de pesquisa: a influência do contexto ambiental nos trabalhadores offshore de uma plataforma petrolífera. Psicologia: Ciência e Profissão, 22 (1), 112-119. doi: 10.1590/S1414-98932002000100012.

Pessanha, R. M. (1994). O trabalho offshore inovação tecnológica, organização do trabalho e qualificação do operador de produção na Bacia de Campos, RJ (Dissertação de Mestrado). Programa de Pós-Graduação em Engenharia de Produção. Universidade Federal do Rio de Janeiro.

Reinert, M. (1990). Alceste - une méthodologie d'analyse des données textuelles et une application: Aurélia de Gérard de Nerval. Bulletin de Méthodologie Sociologique, (26), 24-54.

Salles, D. M. R. (2010). Representações do trabalho: um estudo sobre o regime de confinamento na indústria petrolífera (Tese de Doutorado). Programa de PósGraduação em Administração. Fundação Getúlio Vargas.

Salles, D. M. R., \& Costa, I. S. A. (2013). Representações do trabalho: estudo sobre confinamento na indústria petrolífera. $R A E$. São Paulo, 53 (3), 230-242.

Silva Junior, D. I., \& Ferreira, M. C. (2007). Escala para avaliação de estressores ambientais no contexto offshore (EACOS). Avaliação Psicológica, 6 (2), 139-146.

Souza, A. A. (1996). Perfil do homem offshore: aspectos relevantes nas relações no trabalho e familiares. Cadernos de Pesquisas em Administração. 1 (3), 1-8.

Webster, N., \& McKechnie, J. L. (1978). Webster's New Twentieth Century Dictionary. Collins World. 


\section{Dados sobre os autores:}

- Sabrine Mantuan dos Santos Coutinho: Graduação em Psicologia (2002) e Doutorado em Psicologia (2008) pela Universidade Federal do Espírito Santo/UFES. Professora Adjunta do Departamento de Psicologia da Universidade Federal Fluminense/UFF. Professora Colaboradora do Programa de Pós-Graduação em Psicologia da Universidade Federal do Espírito Santo/UFES.

- Paulo Rogério Meira Menandro: Graduação em Psicologia pela Universidade de Brasília/UnB (1974) e Doutorado em Psicologia (Psicologia Experimental) pela Universidade de São Paulo/USP (1983). Professor Titular aposentado pela Universidade Federal do Espírito Santo/UFES. Professor do Programa de Pós-Graduação em Psicologia da Universidade Federal do Espírito Santo/UFES.

- Ana Carolina Caetano Tavares Moreira: Graduação em Psicologia pela Universidade Federal Fluminense/UFF (2017) e Mestranda em Psicologia no Programa de Pós-Graduação em Psicologia da Universidade Federal do Espírito Santo/UFES.

\section{Agradecimentos:}

FAPERJ (Fundação Carlos Chagas Filho de Amparo à Pesquisa do Estado do Rio de Janeiro). 